\title{
Efficacy of whole-body vibration on low bone density in post-burn patients
}

\author{
DOI: https://doi.org/10.5114/pq.2020.100274
}

\author{
Hesham Galal Mahran \\ Department of Physical Therapy for Surgery, Faculty of Physical Therapy, Cairo University, Giza, Egypt
}

\begin{abstract}
Introduction. To evaluate the effect of whole-body vibration on low bone mineral density in post-burn patients.

Methods. Thirty male post-burn patients were randomly divided into 2 groups. The study group received an intervention of whole-body vibration with following parameters: $30 \mathrm{~Hz}$ as vibration frequency, $4-7 \mathrm{~mm}$ as amplitude range, and $2.28 \mathrm{~g}$ as an acceleration, 3 times per week, 24 weeks, in addition to traditional physiotherapy (exercise program). The control group received traditional physiotherapy (exercise program) only. All patients in both groups were subjected to dual-energy X-ray absorptiometry before and after treatment to estimate the bone mineral density in the lumbar region.

Results. There were significant increases in bone mineral density mean values in both groups $(p<0.05)$. Also, there was a significant increase in bone mineral density mean value in the study group compared with the control group $(p<0.05)$.

Conclusions. Whole-body vibration may have a beneficial effect on low bone mineral density in post-burn patients.

Key words: whole-body vibration, bone density, burn
\end{abstract}

\section{Introduction}

Destruction of the skin by a burn injury facilitates the entrance of external pathogenic microorganisms to the bloodstream and stimulates a systemic inflammatory reaction, in turn leading to the production of inflammation-related cytokines by mononuclear cells of peripheral blood [1]. This allows myelopoietic bone marrow production [2], maintains the inflammatory response, and encourages osteoblast production of the RANK ligand, which plays a role in the differentiation of bone marrow stem cells and increases osteoclastogenesis. During severe burns, more than $7 \%$ of the vertebral bone mineral density (BMD) is lost within 3-6 weeks of the injury and about $3 \%$ of the total body bone content is lost during the first 6 months after the injury [3].

It is thought that trabecular bone may be more affected than cortical bone so vertebrae are more affected as they are mainly composed of trabecular bone. Immobilization is also a contributing factor for bone loss [4]. The mechanism is not very clear but it may be related to an increase of the sympathetic tone, which could be part of the stress response [1].

Stress response associated with severe burns increases serum levels of protein, cortisol, and catecholamines, as well as insulin resistance, which activates beta-2 adrenergic receptors that stimulate the RANK ligand production [5]; these are the main causes of skeletal, muscle, and protein catabolism [6].

The upregulation of the parathyroid sensitive calcium receptor by inflammation-related cytokines such as tumour necrosis factor alpha and interleukin 1 is accompanied by changes in calcium metabolism and bone matrix quality. These pathological changes are thought to be responsible for hypercalciuria, hyperparathyroidism, and sequelae [7].

Vitamin $D$ deficiency is common in burn patients and considered as another factor contributing to osteopenia, BMD reduction, and increased fracture incidence in children after severe thermal damage $[1,7]$. It is maintained that post-burn bone loss may also affect adults [8].

The risk of bone fractures is higher in patients with osteoporosis, which increases the morbidity and mortality rate. Currently, the treatment for low bone density is mainly pharmacological. The need for lifelong management, minor side effects, and costs enforce researchers to investigate other treatments. In the treatment of osteoporosis, physiotherapy can improve the patient's life quality and decrease the falling risk, reducing the related fracture incidence [9]. Although therapeutic exercise is considered as a strategy widely used to enhance muscle strength and flexibility and prevent bone loss, there are contradictory results between different forms of exercise [10]. Physical activity safety is an important aspect of treating patients with osteoporosis because of the increased risk of falling [11].

Whole-body vibration (WBV) occurs when the mechanical vibrations which are generated in the platforms are transmitted to the patient's body. WBV is considered as a safe type of physical activity [12]. There are, though, inconsistencies in the literature for the effects of WBV on BMD [13], and the protocols are not uniform owing to different mechanical vibration parameters used and other physical parameters; moreover, mechanical vibration impact may vary depending on posture and anatomy [14]. Also, in some previous studies, combined treatment with drugs and WBV exercise was tested [15]. As there are no studies concerning the role of physiotherapy in osteoporosis after burn, and from the above-mentioned WBV-related issues, the purpose of this study was to evaluate the effectiveness of WBV on low BMD after burn, taking in consideration no drug taking during treatment, one postural attitude, and one region test assigned; the lumbar region was under test from the vertical upright posture during the whole study treatment.

Correspondence address: Hesham Galal Mahran, Department of Physical Therapy for Surgery, Faculty of Physical Therapy, Cairo University, 7 Ahmed ELzayat St. Bien Elsarayat, Dokky, Giza, Egypt, e-mail: heshammahran75@yahoo.com 


\section{Subjects and methods}

Subjects

\section{Inclusion criteria}

Thirty male post-burn patients who met the study inclusion criteria throughout medical reports prepared by physical therapists in the burn unit and agreed to participate in the study were referred from the burn unit in Al Nour Specialist Hospital in Mecca, Saudi Arabia to the physiotherapy department in the same hospital. Post-burn patients were 25-50 years old and had thermal burn injuries of $2^{\text {nd }}-3^{\text {rd }}$ degree extended from the lower area of trunk to the lower extremities, and with the affected total body surface area of $30-45 \%$. In the early burn stage (30-45 days in burn units), all patients were subjected to a unified physical therapy program consisted of positioning, range of motion, and gentle stretching exercises.

\section{Exclusion criteria}

Patients with the following criteria were excluded: any history of endocrine, metabolic or other systemic diseases; prior or ongoing supplementation with calcium; previous or current bone-specific drugs or diseases affecting bone metabolism; smoking; any neurogenic disorder impairing sensory or motor function; use of drugs known to affect the central nervous system or equilibrium; previous brain injury or any disease affecting balance; history of epilepsy; previous or habitual high-intensity exercise; lower extremity arthralgia; lower extremity implant; recent surgeries for heart or spine; cancer; hernia; acute thrombosis; kidney or bladder stones; diabetes; serious cardiovascular or cerebrovascular disease.

\section{Initial evaluation}

All included patients were referred to the evaluation room at the physical therapy department at Al Nour Specialist Hospital in Mecca, Saudi Arabia for determination of BMD and T-score of the lumbar vertebrae. The bone mineral density test was performed by using dual-energy X-ray absorptiometry (DXA) (Hologic Discovery DXA scanner, USA). After the DXA assessment, T-scores and BMD $\left(\mathrm{g} / \mathrm{cm}^{2}\right)$ values were collected. T-score values ranging from -1 to $<-2.5$ were considered as low BMD, as explained in Table 1.

\section{Randomization}

The study was a randomized controlled study. After the initial evaluation, the patients were randomly distributed into 2 groups. The WBV group were subjected to training on a platform of vibration (Power Plate International, Irvine, CA, USA) in addition to a traditional physical therapy program (exercise program), and the control group received the same traditional physical therapy program (exercise program) without vibration.

\section{Treatment intervention}

\section{Whole-body vibration training}

In the WBV group, the training program started with individual supervision and instruction for each patient on how to use the WBV platform. The program of gradual training was divided into 3 time intervals; each time, an additional set was added [16]. The $1^{\text {st }}$ time ( $1^{\text {st }} 8$ weeks) consisted of 2 sets/ session, 3 sessions/week, and a total duration of each session was $10 \mathrm{~min}$. The $2^{\text {nd }}$ time ( $2^{\text {nd }} 8$ weeks) consisted of 3 sets/ session, 3 sessions/week, and a total duration of each session was $15 \mathrm{~min}$. The $3^{\text {rd }}$ time ( $3^{\text {rd }} 8$ weeks) consisted of 4 sets/ session, 3 sessions/week, and a total session duration was $20 \mathrm{~min}$. Each set time was $5 \mathrm{~min}$; the total rest duration between the exercise sets were equal to the total exercise duration. The frequency of vibration was set at $30 \mathrm{~Hz}$ [17-20] throughout the whole study, with the amplitude produced ranging from 4 to $7 \mathrm{~mm}$ [21] (4-5 $\mathrm{mm}$ of vibration amplitude in the $1^{\text {st }} 8$ weeks, $5-6 \mathrm{~mm}$ in the $2^{\text {nd }} 8$ weeks, and $6-7 \mathrm{~mm}$ in the $3^{\text {rd }} 8$ weeks) [19]. The vibration acceleration equalled $2.28 \mathrm{~g}[18,20]$.

\section{Traditional physiotherapy program (exercise program)}

Both the study group and the control group received gradual exercise program selected from a previous study [22] (range of motion exercise, stretching exercise for lower limb and back muscles, ambulance exercises, isotonic and isometric exercises for trunk and lower limbs). Since discharging from the burn unit till the end of the study treatment in each time, each patient executed the following package of regional gradual exercises 3 times/week:

- Trunk exercises: graduated exercises of trunk flexionextension, lateral flexion and rotation exercises, bridge exercises, and graduated ambulance exercises.

Table 1. Patients' demographic and baseline data

\begin{tabular}{|c|c|c|}
\hline Characteristics & WBV group $(n=15)($ mean $\pm S D)$ & Control group $(n=15)($ mean $\pm S D)$ \\
\hline Age (years) & $34.9 \pm 8.1$ & $37.8 \pm 9.3$ \\
\hline Gender & Male & Male \\
\hline $\mathrm{BMI}\left(\mathrm{kg} / \mathrm{m}^{2}\right)$ & $24.26 \pm 2.9$ & $25.8 \pm 4.5$ \\
\hline T-score $(-1$ to $<-2.5)$ & $-2.19 \pm 0.68$ & $-2.24 \pm 0.71$ \\
\hline Osteopenia (T-score: -1 to -2.5 ) & 8 patients & 8 patients \\
\hline Osteoporosis (T-score: <-2.5) & 7 patients & 7 patients \\
\hline $\operatorname{BMD}\left(\mathrm{g} / \mathrm{cm}^{2}\right)$ & $0.83 \pm 0.08$ & $0.82 \pm 0.09$ \\
\hline Time in the burn unit (days) & $37.53 \pm 4.80$ & $36.86 \pm 5.31$ \\
\hline TBSA affected & $30-45 \%$ & $30-45 \%$ \\
\hline Degree of burn & $2^{\text {nd }}-3^{\text {rd }}$ & $2^{\text {nd }}-3^{\text {rd }}$ \\
\hline
\end{tabular}


- Hip exercises: isometric hip exercises (abduction, adduction, extension, and flexion), passive range of motion exercises graduated to active-assisted and then to active exercises, graduated stretching and strengthening exercises for hip muscles.

- Knee exercises: isometric knee exercises, passive range of motion exercises graduated to active-assisted and then to active exercises, graduated strengthening and stretching exercises.

- Ankle exercises: passive range of motion exercises graduated to active-assisted and then to active exercises, graduated strengthening and stretching exercises, mobilization exercises for the tarsal and metatarsal joint.

All exercise guidelines and parameters (type, duration, and intensity) for all patients were checked for avoiding any discrepancies between the 2 groups and all participants were asked not to train during the rest of the week.

Follow-up evaluation

After 24 weeks ( 6 months) of treatment, the lumbar region of each patient was re-assessed with DXA to measure BMD.

\section{Statistical procedures}

After collecting the outcome measures, the SPSS program (v. 16) was used for the analysis. Means and standard deviations were estimated. Unpaired $t$-test and paired $t$-test were utilized to compare mean values between groups and within groups, respectively. Where the value of $p$ was less than 0.05 , the differences between means were considered significant.

\section{Ethical approval}

The research related to human use has complied with all the relevant national regulations and institutional policies, has followed the tenets of the Declaration of Helsinki, and has been approved by the Ethics Committee of the Faculty of Physical Therapy, Cairo University.

\section{Informed consent}

Informed consent has been obtained from all individuals included in this study.

\section{Results}

\section{Initial evaluation results}

Thirty post-burn male patients who suffered from low BMD were included in this study and randomly assigned to 2 equal groups: the WBV group and the control group. The demographic and baseline data for both groups were presented in Table 1. The mean value of age was $34.9 \pm 8.1$ years in the WBV group and $37.8 \pm 9.3$ years in the control group. Mean body mass index equalled $24.26 \pm 2.9 \mathrm{~kg} / \mathrm{m}^{2}$ in the WBV group and $25.8 \pm 4.5 \mathrm{~kg} / \mathrm{m}^{2}$ in the control group. T-score mean value was $-2.19 \pm 0.68$ in the WBV group and $-2.24 \pm 0.71$ in the control group. Both groups had an equal number of patients with osteopenia (8 patients with T-scores ranging from -1 to -2.5$)$, as well as an equal number of patients with osteoporosis (7 patients with T-scores $<-2.5)$. Mean BMD was $0.83 \pm 0.08 \mathrm{~g} / \mathrm{cm}^{2}$ in the WBV group and $0.82 \pm 0.09 \mathrm{~g} / \mathrm{cm}^{2}$ in the control group. Also, Table $1 \mathrm{men}-$ tioned data related to the thermal burn. The mean time of the early phase of thermal injury in the burn unit lasted $37.53 \pm$ 4.80 days in the WBV group and $36.86 \pm 5.31$ days in the control group, the total burn area ranged from $30 \%$ to $45 \%$ in both groups, and the burn degree ranged from the $2^{\text {nd }}$ to the $3^{\text {rd }}$ in both groups. There were no significant differences between the groups considering all patients' demographic or baseline data $(p>0.05)$.

\section{Follow-up evaluation results}

\section{Within groups}

As shown in Table 2 and Figure 1, there were significant increases in BMD in both groups. The mean BMD value presented a highly significant change from $0.83 \pm 0.08 \mathrm{~g} / \mathrm{cm}^{2}$

Table 2. Comparison of mean bone mineral densities within groups and between groups

\begin{tabular}{|l|c|c|c|c|}
\cline { 2 - 5 } \multicolumn{1}{c|}{} & $\begin{array}{c}\text { BMD: } \\
\text { WBV group }\end{array}$ & $\begin{array}{c}\text { BMD: } \\
\text { control group }\end{array}$ & $p$ & $t$ \\
\hline Before treatment & $0.83 \pm 0.08 \mathrm{~g} / \mathrm{cm}^{2}$ & $0.82 \pm 0.09 \mathrm{~g} / \mathrm{cm}^{2}$ & 0.36 & 0.72 \\
\hline After treatment & $1.05 \pm 0.11 \mathrm{~g} / \mathrm{cm}^{2}$ & $0.89 \pm 0.08 \mathrm{~g} / \mathrm{cm}^{2}$ & $<0.001$ & 4.2 \\
\hline$p$ & $<0.001$ & $<0.001$ & & \\
\hline$t$ & -7.9 & 5.77 & & \\
\hline
\end{tabular}

BMD - bone mineral density, WBV - whole-body vibration

$\mathrm{BMD}$ - bone mineral density WBV - whole-body vibration

Figure 1. Mean bone mineral densities in both groups

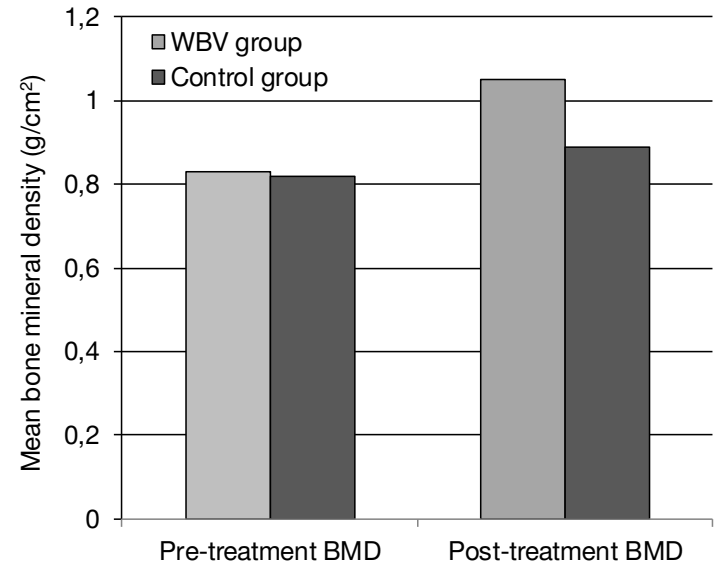


Table 3. Comparison of mean T-scores within groups and between groups

\begin{tabular}{|c|c|c|c|c|}
\hline & $\begin{array}{c}\text { T-score: } \\
\text { WBV group }\end{array}$ & $\begin{array}{c}\text { T-score: } \\
\text { control group }\end{array}$ & $p$ & $t$ \\
\hline Before treatment & $-2.19 \pm 0.68$ & $-2.24 \pm 0.71$ & 0.85 & 0.94 \\
\hline After treatment & $-1.58 \pm 0.65$ & $-2.08 \pm 0.67$ & 0.049 & -2.05 \\
\hline$p$ & $<0.001$ & 0.001 & & \\
\hline$t$ & -10.1 & -4.5 & & \\
\hline
\end{tabular}

WBV - whole-body vibration

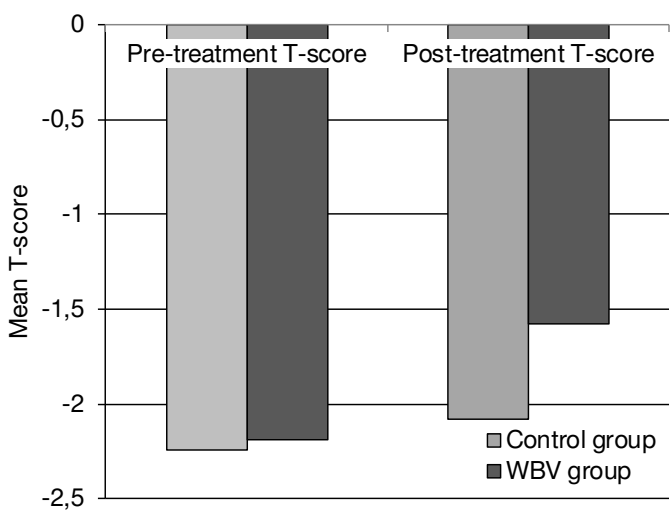

WBV - whole-body vibration

Figure 2. Mean T-scores in both groups

before treatment to $1.05 \pm 0.11 \mathrm{~g} / \mathrm{cm}^{2}$ after treatment in the WBV group $(p<0.001)$ and from $0.82 \pm 0.09 \mathrm{~g} / \mathrm{cm}^{2}$ before treatment to $0.89 \pm 0.08 \mathrm{~g} / \mathrm{cm}^{2}$ after treatment in the control group $(p<0.001)$. As demonstrated in Table 3 and Figure 2, a highly significant change of T-score mean value was observed from $-2.19 \pm 0.68$ before treatment to $-1.58 \pm 0.65$ after treatment in the WBV group $(p<0.001)$, and there was a significant change of mean T-score from $-2.24 \pm 0.71$ before treatment to $-2.08 \pm 0.67$ after treatment in the control group $(p=0.001)$.

\section{Between groups}

As demonstrated in Table 2 and Figure 1, there was a significant between-group difference in mean BMD after treatment: the value equalled $1.05 \pm 0.11 \mathrm{~g} / \mathrm{cm}^{2}$ in the WBV group and $0.89 \pm 0.08 \mathrm{~g} / \mathrm{cm}^{2}$ in the control group $(p<0.001)$. As presented in Table 3 and Figure 2, there was a significant between-group difference in mean T-scores after treatment: the value equalled $-1.58 \pm 0.65$ in the WBV group and -2.08 \pm 0.67 in the control group $(p=0.049)$.

\section{Discussion}

After 6 months of treatment, lumbar spine (L2-L4) BMD significantly increased in both patient groups (all $p<0.01$ ). As an indicator for BMD improvement throughout the body, the increase in lumbar spine BMD was higher in the WBV group than in the control group $(p<0.001)$, which may be attributed to the WBV treatment.

There are some discrepancies and conflicting results in the literature related to using WBV training on low BMD, and the causes for these results can be explained as follows. Regardless of the total number of sessions, there is a positive relationship between the total time that subjects are placed on the platform of WBV (cumulative dose) and the BMD improvement $[17,23]$. So, a significant improvement in BMD is more relevant to the training session number per week. Also, BMD improvement with WBV may depend on several other factors, such as amplitude, loading frequency, and rest periods, which may interact with one another [24].

In the current study, WBV with frequencies of more than $20 \mathrm{~Hz}$ and amplitude ranging from 4 to $7 \mathrm{~mm}$ resulted in an improvement of lumbar spine BMD. This is consistent with previous studies which indicated that the training stimulus was not effective when frequencies below $20 \mathrm{~Hz}$ were applied [25, 26]. Also, efficient transfer of energy to the spine required a smaller amplitude of vibrating stimuli with high frequency. Therefore, the use of frequencies of more than $20 \mathrm{~Hz}$ is recommended [27]. This is also consistent with other studies that resulted in statistical improvements in long sessions [28, 29].

In several previous studies, a BMD improvement was observed after WBV $[17,28]$, while no post-treatment improvement with WBV was shown by others [30, 31]. Ruan et al. [28] observed an increase of $4.3 \%$ in the lumbar spine $\mathrm{BMD}$ and an improvement of $3.2 \%$ in the femoral neck BMD after 6 months of treatment with WBV. Karakiriou et al. [32] reported no change in the lumbar spine BMD in the WBV group, but detected a decrease in the lumbar spine BMD in the control group, suggesting that WBV might have contributed to the maintenance of BMD. In contrast, Davis et al. [31] found no change in BMD in any of the WBV groups of postmenopausal patients: low-intensity vibration, high-intensity vibration, or control groups.

WBV exercise is also an active strategy of Innovative Comprehensive Active Rehabilitation of Osteoporosis (ICARO), described by Weber-Rajek et al. [33] as focused on increasing $B M D$, slowing the progression of the disease, and limiting its consequences.

It is believed that bone tissue micro-trauma produced by vibrating stimuli stimulates osteoblast action for repairing [34] and enhances bone formation after WBV. Also, it was noticed that growth hormone and testosterone levels in men and women improved after WBV training [35-37]. Oliveira et al. [38] found a significant effect of WBV intervention on lumbar spine BMD in comparison with a group without intervention.

Different mechanical vibration mechanisms focus on preventing deterioration and increasing or maintaining BMD [39]. Frequent loading exercise stimulates the flow of the fluid in bone lacunae and canaliculi. Sufficient and effective mechanical stress, as well as muscle contraction acting on bone during physical activity adequately influence mechanotransduction to increase fluid flow in the bone [39, 40].

Recently, sclerostin expression has shown the influence of osteocytes on bone and muscle activation stimuli. Sclerostin plays a role in the inhibition of osteoblastic bone formation [41]. Bone disorders that affect mutations in the SOST gene, encoding sclerostin, such as sclerostosis and van Buchem disease, produce a high BMD and a low risk of fractures [42]. Exercise and mechanical loading of the skeleton can stimulate bone formation, while immobilization increases 
sclerostin-positive osteocytes and inhibits bone formation. Osteocytes can recognize and respond to the mechanical stresses that lead to bone formation [43]. Sclerostin serum measurements seem to be important in explaining different ways by which bone cells react to various stimuli, such as hormonal, physical (in the form of mechanical vibration), and pharmacological ones [41].

The interaction of mechanical vibrations with body structures induces bone formation process; the mechanism of action may be related to the piezoelectric theory [43]. Also, WBV can affect the levels of different hormones, such as growth hormone, parathyroid hormone, and serum testosterone $[18,40]$, which can prevent osteoporosis and sarcopenia $[39,44]$.

\section{Limitations}

The limitation may be the number of patients in each group, as well as treatment duration. An increased number of patients and prolonged treatment may enforce the results.

\section{Conclusions}

WBV may have a beneficial effect on BMD in post-burn patients.

\section{Disclosure statement}

The author does not have any financial interest and did not receive any financial benefit from this research.

\section{Conflict of interest}

The author states no conflict of interest.

\section{References}

1. Klein GL, Herndon DN, Goodman WG, Langman CB, Phillips WA, Dickson IR. Histomorphometric and biochemical characterization of bone following acute severe burns in children. Bone. 1995;17(5):455-460; doi: 10.1016/8756-3282(95)00279-1.

2. Chou DB, Sworder B, Bouladoux N, Roy CN, Uchida AM, Grigg $M$, et al. Stromal-derived IL-6 alters the balance of myeloerythroid progenitors during Toxoplasma gondii infection. J Leukoc Biol. 2012;92(1):123-131; doi: 10.1189/jlb.1011527.

3. Klein GL, Wimalawansa SJ, Kulkarni G, Sherrard DJ, Sanford AP, Herndon DN. The efficacy of acute administration of pamidronate on the conservation of bone mass following severe burn injury in children: a doubleblind, randomized, controlled study. Osteoporos Int. 2005; 16(6):631-635; doi: 10.1007/s00198-004-1731-1.

4. Klein GL, Xie Y, Qin Y-X, Lin L, Hu M, Enkhbaatar P. Preliminary evidence of early bone resorption in a sheep model of acute burn injury: an observational study. $\mathrm{J}$ Bone Miner Metab. 2014;32(2):136-141; doi: 10.1007/ s00774-013-0483-4.

5. Gauglitz GG, Herndon DN, Kulp GA, Meyer WJ 3rd, Jeschke MG. Abnormal insulin sensitivity persists up to three years in pediatric patients post-burn. J Clin Endocrinol Metab. 2009;94(5):1656-1664; doi: 10.1210/ jc.2008-1947.

6. Porter C, Hurren NM, Herndon DN, Børsheim E. Whole body and skeletal muscle protein turnover in recovery from burns. Int J Burns Trauma. 2013;3(1):9-17.

7. Murphey ED, Chattopadhyay N, Bai M, Kifor O, Harper D, Traber DL, et al. Up-regulation of the parathyroid calciumsensing receptor after burn injury in sheep: a potential contributory factor to postburn hypocalcemia. Crit Care Med. 2000;28(12):3885-3890; doi: 10.1097/00003246200012000-00024.

8. Rousseau A-F, Foidart-Desalle M, Ledoux D, Remy C, Croisier J-L, Damas P, et al. Effects of cholecalciferol supplementation and optimized calcium intakes on vitamin D status, muscle strength and bone health: a oneyear pilot randomized controlled trial in adults with severe burns. Burns. 2015;41(2):317-325; doi: 10.1016/j. burns.2014.07.005.

9. Rizzoli R, Reginster J-Y, Arnal J-F, Bautmans I, Beaudart C, Bischoff-Ferrari $\mathrm{H}$, et al. Quality of life in sarcopenia and frailty. Calcif Tissue Int. 2013;93(2):101-120; doi: 10.1007/s00223-013-9758-y.

10. Sota T, Matsuo S, Uchida Y, Hagino H, Kawai Y. Effects of lower body positive pressure on cardiovascular responses during walking in elderly women. Physiol Res. 2013;62(6):653-662; doi: 10.33549/physiolres.932459.

11. Gerdhem P. Osteoporosis and fragility fractures: vertebral fractures. Best Pract Res Clin Rheumatol. 2013;27(6): 743-755; doi: 10.1016/j.berh.2014.01.002.

12. Sá-Caputo D, Ronikeili-Costa $P$, Carvalho-Lima RP, Bernardo LC, Bravo-Monteiro MO, Costa R, et al. Whole body vibration exercises and the improvement of the flexibility in patient with metabolic syndrome. Rehabil Res Pract. 2014;2014:628518; doi: 10.1155/2014/628518.

13. Kiiski J, Heinonen A, Järvinen TL, Kannus P, Sievänen H. Transmission of vertical whole body vibration to the human body. J Bone Miner Res. 2008;23(8):1318-1325; doi: 10.1359/jbmr.080315.

14. Slatkovska L, Alibhai SMH, Beyene J, Cheung AM. Effect of whole-body vibration on BMD: a systematic review and meta-analysis. Osteoporos Int. 2010;21(12):19691980; doi: 10.1007/s00198-010-1228-z.

15. Iwamoto J, Sato Y, Takeda T, Matsumoto H. Whole body vibration exercise improves body balance and walking velocity in postmenopausal osteoporotic women treated with alendronate: Galileo and Alendronate Intervention Trail (GAIT). J Musculoskelet Neuronal Interact. 2012; 12(3):136-143.

16. Zaki ME. Effects of whole body vibration and resistance training on bone mineral density and anthropometry in obese postmenopausal women. J Osteoporos. 2014;2014:702589; doi: 10.1155/2014/702589.

17. Lai C-L, Tseng S-Y, Chen C-N, Liao W-C, Wang C-H, Lee $M-C$, et al. Effect of 6 months of whole body vibration on lumbar spine bone density in postmenopausal women: a randomized controlled trial. Clin Interv Aging. 2013;8:1603-1609; doi: 10.2147/cia.s53591.

18. Bemben DA, Palmer IJ, Bemben MG, Knehans AW. Effects of combined whole-body vibration and resistance training on muscular strength and bone metabolism in postmenopausal women. Bone. 2010;47(3):650-656; doi: 10.1016/j.bone.2010.06.019.

19. Ebid AA, Ahmed MT, Mahmoud Eid M, Mohamed MSE. Effect of whole body vibration on leg muscle strength after healed burns: a randomized controlled trial. Burns. 2012;38(7):1019-1026; doi:10.1016/j.burns.2012.02.006.

20. Verschueren SMP, Bogaerts A, Delecluse C, Claessens AL, Haentjens P, Vanderschueren D, et al. The effects of whole-body vibration training and vitamin $D$ supplementation on muscle strength, muscle mass, and bone density in institutionalized elderly women: a 6-month randomized, controlled trial. J Bone Miner Res. 2011; 26(1):42-49; doi: 10.1002/jbmr.181. 
21. Stolzenberg N, Belavý DL, Rawer R, Felsenberg D. Wholebody vibration versus proprioceptive training on postural control in post-menopausal osteopenic women. Gait Posture. 2013;38(3):416-420; doi: 10.1016/j.gaitpost.2013.01.002.

22. Yurdalan SU, Ünlü B, Seyyah M, Şenyıldız B, Çetin YK, Çimen M. Effects of structured home-based exercise program on depression status and quality of life in burn patients. Burns. 2018;44(5):1287-1293; doi: 10.1016/j. burns.2018.02.015.

23. Fratini A, Bonci T, Bull AMJ. Whole body vibration treatments in postmenopausal women can improve bone mineral density: results of a stimulus focused metaanalysis. PLoS One. 2016;11(12):e0166774; doi: 10.1371/ journal.pone.0166774.

24. Turner $\mathrm{CH}$, Robling AG. Designing exercise regimens to increase bone strength. Exerc Sport Sci Rev. 2003; 31(1):45-50; doi: 10.1097/00003677-200301000-00009.

25. Kleinöder H, Mester J. Safety and performance optimization in vibration training [in German]. BISp-Jahrbuch. 2003;253-258.

26. Yue Z, Mester J. A modal analysis of resonance during the whole-body vibration. Stud Appl Math. 2004;112(3): 293-314; doi: 10.1111/j.0022-2526.2004.01513.x.

27. Rubin C, Pope M, Fritton JC, Magnusson M, Hansson T, McLeod K. Transmissibility of 15-hertz to 35-hertz vibrations to the human hip and lumbar spine: determining the physiologic feasibility of delivering low-level anabolic mechanical stimuli to skeletal regions at greatest risk of fracture because of osteoporosis. Spine. 2003;28(23): 2621-2627; doi: 10.1097/01.brs.0000102682.61791.c9.

28. Ruan X-Y, Jin F-Y, Liu Y-L, Peng Z-L, Sun Y-G. Effects of vibration therapy on bone mineral density in postmenopausal women with osteoporosis. Chin Med J. 2008; 121(13):1155-1158; doi: 10.1097/00029330-200807010 -00001 .

29. Verschueren SMP, Roelants M, Delecluse C, Swinnen S, Vanderschueren D, Boonen S. Effect of 6 -month whole body vibration training on hip density, muscle strength, and postural control in postmenopausal women: a randomized controlled pilot study. J Bone Miner Res. 2004;19(3):352-359; doi: 10.1359/jbmr.0301245.

30. Marín-Cascales E, Rubio-Arias JA, Romero-Arenas S, Alcaraz PE. Effect of 12 weeks of whole-body vibration versus multi-component training in post-menopausal women. Rejuvenation Res. 2015;18(6):508-516; doi: 10.1089/rej.2015.1681.

31. Davis R, Rowe J, Nichols DL, Sanborn CF, DiMarco NM, Pavlovic A. Effects of two intensities of whole body vibration on fall related risk factors in postmenopausal women. J Womens Health Issues Care. 2014;3(6); doi: 10.4172/2325-9795.1000167.

32. Karakiriou SK, Douda HT, Smilios IG, Volaklis KA, Tokmakidis SP. Effects of vibration and exercise training on bone mineral density and muscle strength in post-menopausal women. Eur J Sport Sci. 2012;12(1):81-88; doi: 10.1080/17461391.2010.536581.

33. Weber-Rajek M, Mieszkowski J, Niespodziński B, Ciechanowska K. Whole-body vibration exercise in postmenopausal osteoporosis. Prz Menopauzalny. 2015; 14(1):41-47; doi: 10.5114/pm.2015.48679.

34. Burr DB, Martin RB, Schaffler MB, Radin EL. Bone remodeling in response to in vivo fatigue microdamage. J Biomech. 1985;18(3):189-200; doi: 10.1016/00219290(85)90204-0.
35. Murphy S, Khaw KT, Cassidy A, Compston JE. Sex hormones and bone mineral density in elderly men. Bone Miner. 1993;20(2):133-140; doi: 10.1016/s0169-6009 (08)80022-0.

36. Kelly PJ, Pocock NA, Sambrook PN, Eisman JA. Dietary calcium, sex hormones, and bone mineral density in men. BMJ. 1990;300(6736):1361-1364; doi: 10.1136/bmj.300. 6736.1361.

37. Greendale GA, Edelstein S, Barrett-Connor E. Endogenous sex steroids and bone mineral density in older women and men: the Rancho Bernardo Study. J Bone Miner Res. 1997;12(11):1833-1843; doi: 10.1359/jbmr. 1997.12.11.1833.

38. Oliveira LC, Oliveira RG, Pires-Oliveira DAA. Effects of whole body vibration on bone mineral density in postmenopausal women: a systematic review and metaanalysis. Osteoporos Int. 2016;27(10):2913-2933; doi: 10.1007/s00198-016-3618-3.

39. Rauch F. Vibration therapy. Dev Med Child Neurol. 2009;51(Suppl. 4):166-168; doi: 10.1111/j.1469-8749. 2009.03418.x.

40. Totosy de Zepetnek JO, Giangregorio LM, Craven BC. Whole-body vibration as potential intervention for people with low bone mineral density and osteoporosis: a review. J Rehabil Res Dev. 2009;46(4):529-542; doi: 10.1682/JRRD.2008.09.0136.

41. Yavropoulou MP, Xygonakis C, Lolou M, Karadimou F, Yovos JG. The sclerostin story: from human genetics to the development of novel anabolic treatment for osteoporosis. Hormones. 2014;13(4):476-487; doi: 10.14310/ horm.2002.1552.

42. Sharifi M, Ereifej L, Lewiecki EM. Sclerostin and skeletal health. Rev Endocr Metab Disord. 2015;16(2):149156; doi: 10.1007/s11154-015-9311-6.

43. Çidem M, Karakoç Y, Ekmekçi H, Küçük SH, Uludağ $M$, Gün K, et al. Effects of whole-body vibration on plasma sclerostin level in healthy women. Turk J Med Sci. 2014; 44(3):404-410; doi: 10.3906/sag-1302-88.

44. Von Stengel S, Kemmler W, Bebenek M, Engelke K, Kalender WA. Effects of whole-body vibration training on different devices on bone mineral density. Med Sci Sports Exerc. 2011;43(6):1071-1079; doi: 10.1249/mss.0b013 e318202f3d3. 